\title{
Investigating the high yield extraction of pectin from Crissampelos Pareira L. Vat. Hirsute planted in Vietnam
}

\author{
Nguyen Van Toan ${ }^{1 * 2}$, Duong Xuan Quyen ${ }^{1}$ \\ ${ }^{1}$ Department of Food Technology, School of Biotechnology, International University, \\ ${ }^{2}$ Vietnam National University, Ho Chi Minh City, Vietnam
}

\begin{abstract}
The study on the most suitable extracting conditions of pectin from Crissampelos pareira L. Var. Hirsute was thoroughly and successfully investigated. It was found that the most suitable conditions for the extraction of pectin from $\mathrm{C}$ pareira were at temperature of $90^{\circ} \mathrm{C} ; \mathrm{pH}$ of solution of 1.5 ; and the extraction time of 60 minutes. The average yield of pectin was of $15.58 \%$. it is worth noting that the mentioned extracting conditions showed a highly significant effect $(\mathrm{p}<0.05)$ on the yield of pectin. As the consequence, the equivalent weight, methoxyl content, anhydrouronic acid content, degree of esterification and moisture content of extracted pectin obtained under the suitable conditions were found to be $333.33 \mathrm{~g} / \mathrm{mol}, 5.58 \%, 84.48 \%, 37.5 \%, 15.76 \%$, respectively.
\end{abstract}

Key words: Crissampelos pareira L. Var. Hirsute Extraction, pectin, esterification, methoxyl, methoxylation

\section{Introduction}

Pectin (C6H10O7, M.W. $194.14 \mathrm{~g} / \mathrm{mol}$ ), an anionic biopolymer, is one of the important biopolymers used in the food industry. It is soluble in water and it is one of the major structural polysaccharides of higher plant cells. Pectin has many applications in the food and beverage industry as a thickening and gelling agent, colloidal stabilizer, texturizer, and emulsifier ${ }^{[1,2]}$ and for applying coatings on fresh and cut fruits or vegetables $^{[3,4]}$. Pectin is generally formed of water-soluble pectinic acids with varying methyl ester contents, which are capable of forming gels alongside sugar and acid when exposed to the correct conditions ${ }^{[5]}$. Pectin for food technology or pharmaceuticals, especially for colon treatments, has been comprehensively reviewed over time ${ }^{[6,7]}$. Pectin is a high molecular weight branched macromolecule, which can be transformed into a hydrogel, intended as a flexible network of polymeric chains that can swell but not dissolve in water ${ }^{[8]}$.

C. pareira is in the family of Menispermaceae. It is a tropical climbing plant ubiquitous in Asia, East Africa, and South America. The plant is traditionally used for treating skin disorders, abdominal pain, inflammation, dysentery, indigestion, and anorexia ${ }^{[9]}$. Furthermore, the ethanolic and methanolic extracts of $C$. pareira roots effectively scavenge ROS and RNS and prevent acute oxidative tissue injury in animal models ${ }^{[10,11]}$ The ethanolic extract of $C$. pareira roots also possess anti-inflammatory properties in acute, subacute, and chronic inflammation, and antinociceptive and antiarthritic activities in rats ${ }^{[12,13]}$ The ethanolic extract of $C$. pareira (whole plant) exhibits analgesic and anti-inflammatory properties in rats ${ }^{[14]}$. In addition, the wholeplant methanolic extract of $C$. pareira is cytotoxic to the MCF-7 human breast cancer cell line ${ }^{[15]}$.

The water extract of fresh $C$. pareira leaves forms gel in a short period of time at room temperature without the need for sucrose or calcium ${ }^{[16,17]}$. The main gelling ingredient of $C$. pareira leaves is low methoxyl pectin (LMP), consisting mainly of galacturonic acid and small amounts of neutral sugars ${ }^{[18]}$. In the food industry, pectin is used as an emulsifier, stabilizer, and thickener, as well as an ingredient in therapeutic diets, such as food gels for patients with diabetes mellitus.

Though, Pectin is commonly found in most of the plant tissues, the number of sources that may be used for the commercial manufacture of pectin is limited. At present, commercial pectins are almost exclusively derived from citrus peel or apple pomace, both of which are by-products from juice manufacturing units. 
Moreover, most of studies about Crissampelos pareira L. Var. Hirsute are related to its medical properties so that investigating the most suitable extraction conditions of pectin from Crissampelos pareira L. Var. Hirsute is necessary to provide wider range of pectin sources. Since $C$. pareire mostly grows in the wild, commonly collected by locals to be used as a refreshment, it requires undemanding cultivation therefore it is applicable to be used as raw material in industrial scale. As a consequence, it is economically important to investigate a possible newer source of pectin from locally grown Crissampelos pareira and investigate the most suitable conditions for pectin extraction including incubation time, extraction temperature, solution $\mathrm{pH}$. In addition, determination of pectin yield extraction, methoxyl content, total anhydrouronic acid contents as well as degree of esterification are of important parameters of the current study.

\section{Materials and Methods \\ Materials}

Fresh Crissampelos pareira L. Var. Hirsute leaves were obtaied from a local market in Ho Chi Minh City and were stored at cool temperature of about $15-18^{\circ} \mathrm{C}$. The chosen leaves which for the experiments were nearly similar in the uniformity of shape and size, had dark green color which meant they were matured and their chemical compositions were fully developed. Leaves that were rotten or damaged by insects or by poor transportation were eliminated.

All reagents that were used in this research including Citric acid, ethanol, phenol red, sodium chloride, hydrochloric acid, sodium hydroxide were purchased from China.

\section{Methods}

\section{Sample preparation and extraction process}

The extraction procedure was adapted from Kratchanova M. et al (2012) ${ }^{[19]}$.

Fresh leaves were sorted and washed first. $25 \mathrm{~g}$ of leaves was weighed and $500 \mathrm{ml}$ of distilled water was added (1:20), then, the mixture was homogenized in blender. Citric acid was added for maintaining different $\mathrm{pH}$ medium as reagents. Afterward, extraction was done by hot water bath under specific conditions of extraction temperature, time and $\mathrm{pH}$ of the solution. During extraction, regularly stirring was needed as well as distilled water addition to replace the loss of water due to evaporation. The hot acid extract was filtered through moistened cheese cloth. With five different $\mathrm{pH}$ medium of extraction at five different range of time and temperature, extractions were carried out and the extracts were collected separately for further analytical methods. The filtrate was immediately cooled to room temperature using ice bath. After the extraction, heating was applied to remove maximum water in the extract, then it was rapidly cooled down to $40^{\circ} \mathrm{C}$ using ice bath. The suspensions were centrifuged at $4^{\circ} \mathrm{C}$ for $15 \mathrm{~min}$ at 5,000 rpm.

Pectin in the extract was coagulated by using an equal volume (1:1) of $95 \%$ ethanol. The mixture was stirred for $5 \mathrm{~min}$ and stored at $4^{\circ} \mathrm{C}$ for 12 hours. The precipitate was collected through centrifugation at $4^{\circ} \mathrm{C}$ for 15 min at 5,000 rpm and filtration using moistened cheese cloth, was washed with 70, 80 and 95\% ethanol. The extracted pectin was dried in a freeze dryer for $24 \mathrm{~h}$, ground and stored in a desiccator until further analysis. Experimental design

Table 1. Experimental design

(Ermias Girma, Teshome Worku,2016) ${ }^{[20]}$

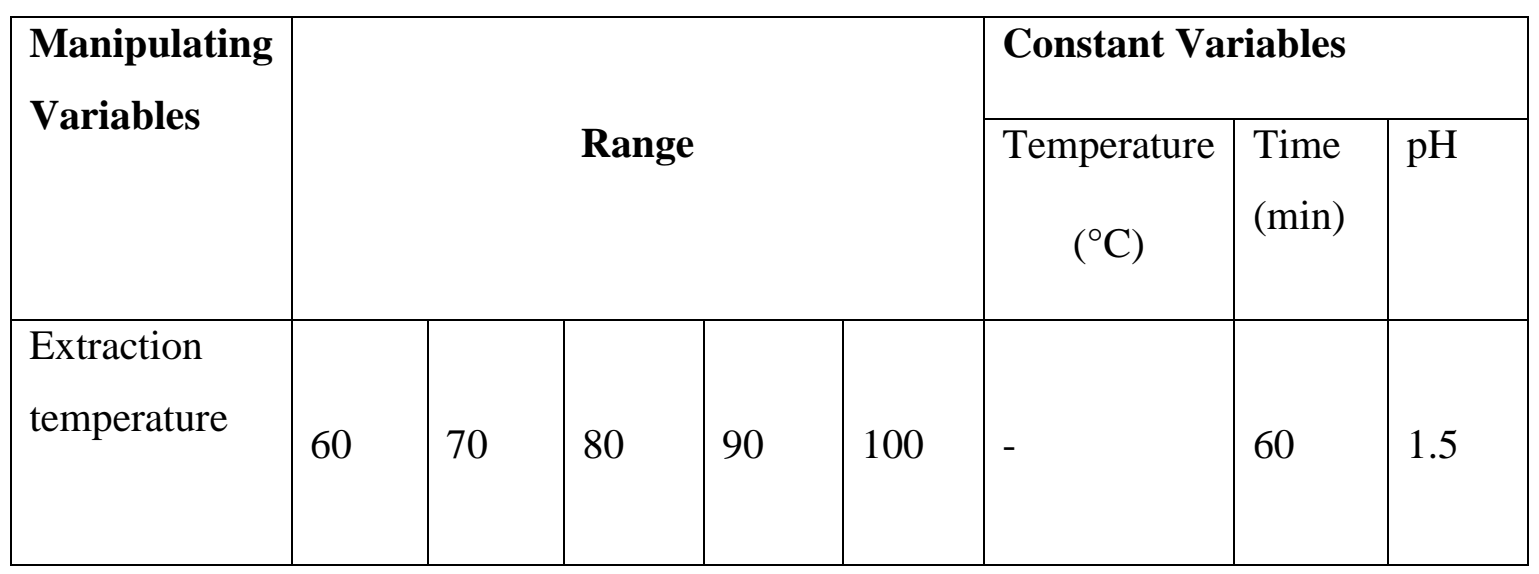




\begin{tabular}{|l|l|l|l|l|l|l|l|l|}
\hline$\left({ }^{\circ} \mathrm{C}\right)$ & & & & & & & & \\
& & & & & & & & \\
\hline $\begin{array}{l}\text { Extraction } \\
\text { time (min) }\end{array}$ & 60 & 90 & 120 & 150 & 180 & 90 & - & 1.5 \\
\hline Solution pH & 1.0 & 1.5 & 2.0 & 2.5 & 3.0 & 90 & 60 & - \\
\hline
\end{tabular}

\section{Determination of yield extraction}

The dried pectin was weighed and calculated as gram of crude extract per gram of sample mass. The yield of pectin extraction is determined using the following:

$$
\text { Yield of extraction }=\frac{\text { Weight of extracted pectin } \times 100}{\text { Weight of fresh sample }}
$$

\section{Determination of moisture content}

Electronic Moisture Balance was used for determination of moisture content

\section{Determination of equivalent weight}

Equivalent weight is used for calculating methoxyl content, the anhydrouronic acid content and degree of esterification. It is determined by titration with sodium hydroxide to $\mathrm{pH} 7.5$ using either phenol red as an indicator.

Equivalent weight was determined by Ranganna's method $(1995)^{[21]} .0 .5 \mathrm{~g}$ of dried pectin was taken in a $250 \mathrm{ml}$ conical flask and $5 \mathrm{ml}$ ethanol was added. $1 \mathrm{~g}$ of sodium chloride to sharpen the end point and 100 $\mathrm{ml}$ of distilled water were added. Finally 6 drops of phenol red was added and titrated against $0.1 \mathrm{~N} \mathrm{NaOH}$. Titration point was indicated by purple color. This neutralized solution was stored for determination of methoxyl content.

$$
\text { Equivalent weight }=\frac{\text { Weight of sample }(\mathrm{mg})}{\text { ml of alkalin } \times \text { Normality of alkalin }}
$$

\section{Determination of methoxyl content (MeO)}

Methoxyl content is a significant factor in controlling the setting time of pectin, the sensitivity to polyvalent cations and their usefulness in the preparation of low solid gels and fibers (Ermias Girma et al., 2016) ${ }^{[20]}$. The Degree of Methylation (DM) is defined as the percentage of carbonyl groups esterified with methanol. Methoxyl content is determined by the saponification of pectin followed by titration of the free carboxyl acid groups (Maazullah Khan et al., 2015) ${ }^{[22]}$.

Determination of $\mathrm{MeO}$ was done by using the Ranganna's method (1995). The neutral solution was collected from determination of equivalent weight, and $25 \mathrm{ml}$ of sodium hydroxide with normality of $0.25 \mathrm{~N}$ was added. The mixed solution was stirred thoroughly and kept at room temperature for $30 \mathrm{~min}$. After 30 min $25 \mathrm{ml}$ of $0.25 \mathrm{~N}$ hydrochloric acid was added and titrated against $0.1 \mathrm{~N} \mathrm{NaOH}$ to the same end point as before like in equivalent weight titration.

The methoxyl content is calculated by below equation:

Where:

$$
\text { Methoxyl content }(\%)=\frac{\text { ml of alkalin } \times \text { Normality of alkalin } \times 31 \times 100}{\text { Weight of sample }(\mathrm{mg})}
$$

Molecular weight of methoxyl (CH3O): 31 


\section{Determination of anhydrouronic acid content (AUA)}

Anhydrouronic acid content (AUA) is essential to determine the purity and degree of esterification. By using the values of the equivalent weight and the methoxyl content, the anhydrouronic acid content is calculated adapting method from Ania A. O. et al.,(2012) ${ }^{[23]}$. Total AUA of pectin is obtained by the following formula (Ermias Girma et al., 2016) ${ }^{[20]}$.

$$
A U A(\%)=\frac{176 \times 0.1 \mathrm{z} \times 100}{W \times 1000}+\frac{176 \times 0.1 y \times 100}{W \times 1000}
$$

Where:

Molecular unit of AUA (1 unit) $=176 \mathrm{~g}$

$\mathrm{z}=\mathrm{ml}$ (titre) of $\mathrm{NaOH}$ from equivalent weight determination

$\mathrm{y}=\mathrm{ml}$ (titre) of $\mathrm{NaOH}$ from methoxyl content determination

$\mathrm{W}=$ weight of sample

\section{Determination of degree of esterification (DE)}

The degree of esterification of pectin refers to the percentage of esterified galacturonic acids out of the total galacturonic acid residues and it usually represents the degree of methoxylation. The degree of esterification of extracted pectin was calculated from methoxyl and anhydrouronic acid content using the following expression (Ania A. O. et al., 2012) ${ }^{[23]}$ :

$$
\text { Degree of esterification }=\frac{176 \times \text { Methoxyl content }(\%) \times 100}{31 \times A U A(\%)}
$$

Where:

Molecular unit of AUA (1 unit) $=176 \mathrm{~g}$

Molecular weight of methoxyl $\left(\mathrm{CH}_{3} \mathrm{O}\right): 31$

\section{Statistical analysis}

The obtained results were calculated as the average of triplicate independent experiments. The ANOVA test at a significant level of $95 \%$ was used to analyze the differences between treatments.

\section{Results and discussion}

\section{Effect of temperature on extraction yield of pectin}

Effect of extraction temperature was studied by manipulating temperature in range of 60 to $100^{\circ} \mathrm{C}$ at constant time of $60 \mathrm{~min}$ and solution $\mathrm{pH}$ kept at 1.5. Figure 1 illustrates the correlation between extraction temperature and the yield of pectin. The pectin yield kept increasing as the temperature increased until reaching its peak when the temperature was at $90^{\circ} \mathrm{C}$. However, when the temperature rose up to $100^{\circ} \mathrm{C}$ its yield reduced. Extraction with very high temperature could induce the hydrolysis of pectin to short-chain sugars, which cannot be precipitated using ethanol thus decreasing the yield of pectin (Canteri-Schemin et al., 2005 ${ }^{[24]}$. From the result it can be concluded that the highest percentage yield of pectin extracted from Crissampelos pareira L. Var. Hirsute leaves using citric acid was $15.58 \%$ with the temperature at $90^{\circ} \mathrm{C}$. 


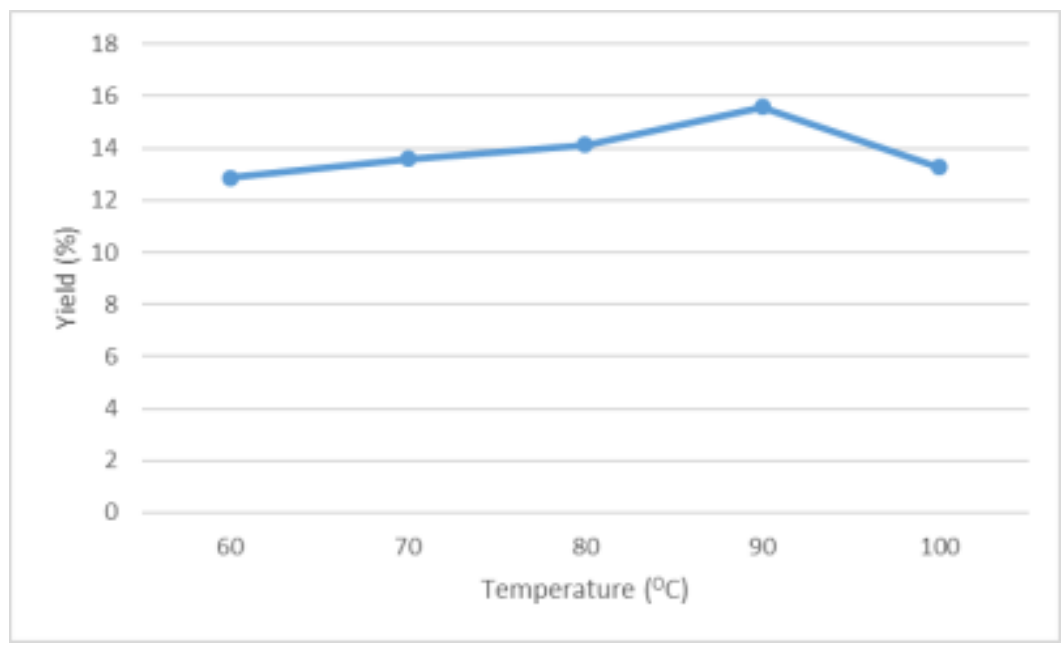

Figure 1. Extraction yield of pectin at different temperature with $\mathrm{pH}$ solution at 1.50 and extraction time 60 $\min$

\section{Effect of time on extraction yield of pectin}

Effect of extraction time was investigated by controlling time from 60 to $180 \mathrm{~min}$ at constant temperature of $90^{\circ} \mathrm{C}$ and solution $\mathrm{pH}$ kept at 1.5 . Figure 2 shows the correlation between extraction time and the yield of pectin. The pectin yield steadily alleviated as the time increased from a high of $15.58 \%$ to a low of $10.36 \%$. Extension of extraction time possibly induced the digestion of pectin in the result of taking a toll on precipitation by ethanol, which led to a fall of pectin yield. In procedure, the duration between when acid was added to the substrate and the ethanol precipitation should be as short as possible in order to prevent the acid from breaking down the glycoside and ester linkage (Xue et al., 2011) ${ }^{[25]}$. In consequence, it could negatively affect gelling property of extracted pectin. According to the result, it was proved that the yield reached its peak of $15.58 \%$ at the time of $60 \mathrm{~min}$.

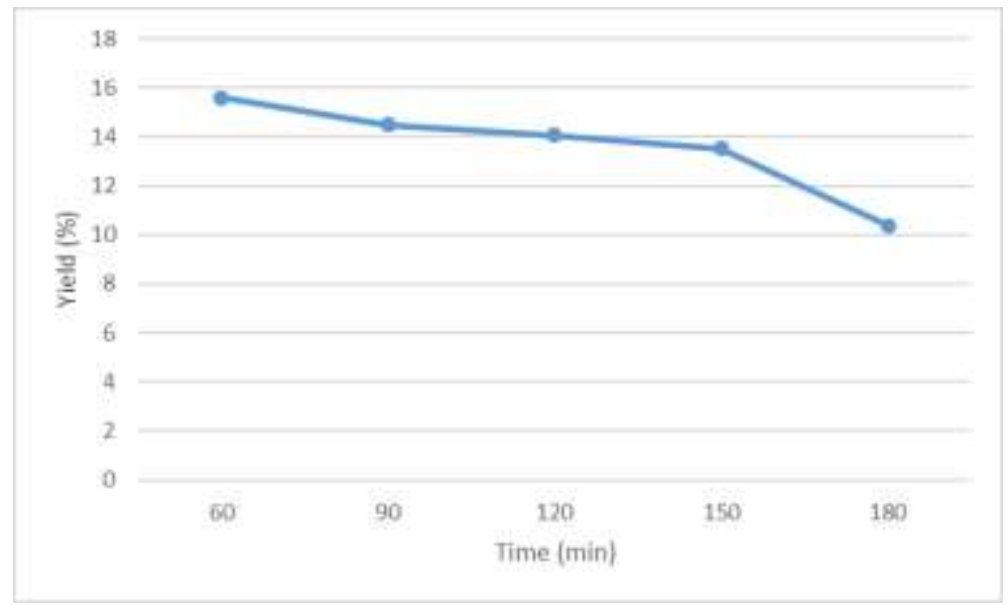

Figure 2. Extraction yield of pectin at different extraction time with $\mathrm{pH}$ solution at 1.50 and extraction temperature at $90^{\circ} \mathrm{C}$

\section{Effect of $\mathrm{pH}$ on extraction yield of pectin}

Pectin extractions were conducted using concentrated citric acid to adjust solution $\mathrm{pH}$ from 1 to 3 at temperature $90{ }^{\circ} \mathrm{C}$ and time 60 min to clarify the effect of solution $\mathrm{pH}$ on the yield of pectin. From Figure 3, it was clearly that at $\mathrm{pH}$ solution 1.5 pectin was collected with its greatest amount with $15.58 \%$. However, from $\mathrm{pH}$ of 2.0 onwards, it faced a slight decline by approximately $2 \%$. This may be because of the fact that high temperature together with low $\mathrm{pH}$ might boost the disruption of hydrogen bonds and ester linkages between pectin and cell wall and then increase the degree of diffusion and pectin extraction (Renard et al., 1995 ${ }^{[26]}$; Masmoudi et al., 2008 ${ }^{[27]}$ ). Some studies claimed that acid type significantly influenced the macromolecular and gelling properties of isolated pectin. 


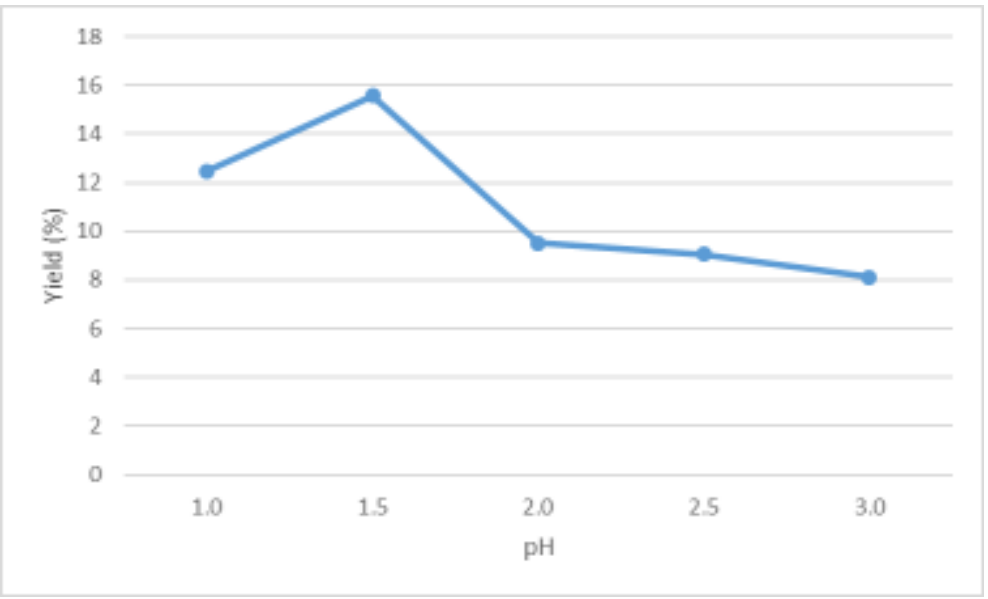

Figure 3. Extraction yield of pectin at different $\mathrm{pH}$ solution with extraction temperature at $90 \mathrm{OC}$ and extraction time $60 \mathrm{~min}$

\section{Moisture content}

The moisture content of pectin extracted from $C$. pareira using citric was found to be $15.76 \%$ which was gradually higher than that of 9.4-11.3\% for commercial pectin. Electronic Moisture Balance was used to conduct this test. The pectin is very hygroscopic so that it must be preserved in closed dry atmosphere.

\section{Equivalent weight}

The equivalent weight of pectin extracted from $C$. pareira using citric was found to be 333.33 . The higher the equivalent weight is, the higher gel forming effect is. This parameter depends on the extraction method and the nature of the materials used for extraction. The lower equivalent weight could be result in higher partial degradation of pectin. The increased or decreased of the equivalent weight might be also dependent upon the amount of free acid (W. Elizabeth Devi, 2014) ${ }^{[28]}$

\section{Methoxyl content (MeO)}

The $\mathrm{MeO}$ of pectin extracted from $C$. pareira using citric was found to be $5.58 \%$. Methoxyl content is a crucial factor in determining the gel formation capacity and controlling the setting time of pectins. Spreading quality and sugar binding capacity of pectin are increased provided that methoxyl content increases (W. Elizabeth Devi, 2014) ${ }^{[28]}$.

\section{Anhydrouronic acid content (AUA)}

The AUA of pectin extracted from $C$. pareira using citric was found to be $84.48 \%$. The AUA demonstrates the purity of the extracted pectin and its value should not be less than 65\% (Food Chemical Codex, 1996. Low value of AUA means that the extracted pectin might have a high amount of protein, starch and sugars in the precipitated pectins (W. Elizabeth Devi, 2014) ${ }^{[28]}$.

\section{Degree of esterification (DE)}

The DE of pectin extracted from $C$. pareira using citric was found to be $37.50 \%$. It was reported that the DE of extracted pectin from $C$. pareira was $39.18 \%$, thus the value obtained in current study was lower than the previously reported value. The degree of esterification determines the behavior of pectin in food applications. Approximately, pectins can be categorized as high methoxy pectins ( $>50 \%$ esterified) and low methoxy pectins ( $<50 \%$ esterified). According to the result, pectin extracted from $C$. pareira was low methoxyl pectin since its DE was lower than 50\%. Degree of esterification decreased with the increase of maturity. The lower DE might be attributed to the conversion of pectins into protopectin which increases the sugars in fresh leaves. DE actually depends on species, tissue and stages of maturity (W. Elizabeth Devi, $2014)^{[28]}$.

\section{Conclusions}


In this study, the Investigating the most suitable extraction conditions of pectin from Crissampelos pareira L. Var. Hirsute was thoroughly and successfully conducted

$>$ Different extraction time, temperature and $\mathrm{pH}$ significantly affected on the yield of pectin.

$>$ The yield of pectin was generally high at the lower set of $\mathrm{pH}$ solution.

$>$ The result indicated that the most suitable condition for pectin extraction was extracting temperature at $90^{\circ} \mathrm{C}$ at $1.5 \mathrm{pH}$ for $60 \mathrm{~min}$ and using citric acid as the extracting solvent, which gave the highest yield with $15.58 \%$.

$>$ From the obtained data, it could easily be seen that the extracted pectin was qualified as its AUA > $65 \%$, and Pectin extracted was HM pectin since its DE $<50 \%$.

\section{Conflicts of intererst}

There is no conflicts of interests.

\section{References}

1. Mesbahi, G.; Jamalian, J.; Farahnaky, A. A comparative study on functional properties of sugar beet and citrus pectins in food systems. Food Hydrocoll. 2005, 19, 731-738.

2. Sriamornsak, P.; Kennedy, R.A. Swelling and diffusion studies of calcium polysaccharide gels intended for film coating. Int. J. Pharm. 2008, 358, 205-213.

3. Rodriguez-Garcia, I.; Cruz-Valenzuela, M.R.; Silva-Espinoza, B.A.; Gonzalez-Aguilar, G.A.; Moctezuma, E.; Gutierrez-Pacheco, M.M.; Tapia-Rodriguez, M.R.; Ortega-Ramirez, L.A.; AyalaZavala, J.F. Oregano (Lippia graveolens) essential oil added within pectin edible coatings prevents fungal decay and increases the antioxidant capacity of treated tomatoes. J. Sci. Food Agric. 2016, 96, 3772-3778.

4. Guerreiro, A.C.; Gago, C.M.L.; Faleiro, M.L.; Miguel, M.G.C.; Antunes, M.D. The e_ect of edible coatings on the nutritional quality of 'Bravo de Esmolfe' fresh-cut apple through shelf-life. LWT 2017, 75, 210-219.

5. Narasimman, P.; Sethuraman, P. An Overview on the Fundamentals of Pectin. Int. J. Adv. Res. 2016, 4, $1855-1860$.

6. Sriamornsak, P. Application of pectin in oral drug delivery. Expert Opin. Drug Deliv. 2011, 8, 10091023.

7. Munarin, F.; Tanzi, M.C.; Petrini, P. Advances in biomedical applications of pectin gels. Int. J. Biol. Macromol.2012, 51, 681-689.

8. Rodsamran, P.; Sothornvit, R. Lime peel pectin integrated with coconut water and lime peel extract as a new bioactive film sachet to retard soybean oil oxidation. Food Hydrocoll. 2019, 97, 105173.

9. G Amresh, CV Rao and PN Singh. Antioxidant activity of Crissampelos pareira on benzo(a)pyreneinduced mucosal injury in mice. Nutr. Res. 2007; 27, 625-32.

10. H Bartsch and $\mathbf{J}$ Nair. Chronic inflammation and oxidative stress in the genesis and perpetuation of cancer: Role of lipid peroxidation, DNA damage, and repair. Langenbecks Arch. Surg. 2006; 391, 499510.

11. A Bafna and S Mishra. Antioxidant and immunomodulatory activity of the alkaloidal fraction of Crissampelos pareira linn. Sci. Pharm. 2010; 78, 21-31.

12. G Amresh, GD Reddy, VR Ch and PN Singh. Evaluation of anti-inflammatory activity of Crissampelos pareira root in rats. J. Ethnopharmacol. 2007; 110, 526-31.

13. [12] G Amresh, PN Singh and VR Ch. Antinociceptive and antiarthritic activity of Crissampelos pareira roots. J. Ethnopharmacol. 2007; 111, 531-6.

14. HM Reza, M Shohel, SB Aziz, FI Pinaz, MF Uddin, M Al-Amin, IN Khan and P Jain. Phytochemical and pharmacological investigation of ethanol extract of Crissampelos pareira. Indian J. Pharm. Sci. $2014 ; 76,455-8$. 
15. BS Thavamani, M Mathew and SP Dhanabal. Anticancer activity of Crissampelos pareira against dalton's lymphoma ascites bearing mice. Pharmacogn. Mag. 2014; 10, 200-6.

16. A Arkarapanthu, V Chavasit, P Sungpuag and L Phuphathanaphong. Gel extracted from Khruea-ma-noi (Cyclea barbata Miers) leaves: Chemical composition and gelation properties. J. Sci. Food Agr. 2005; $85,1741-9$.

17. J Singthong, S Ningsanond, SW Cui and HD Goff. Extraction and physicochemical characterization of Krueo Ma Noy pectin. Food Hydrocolloid 2005; 19, 793-801.

18. J Singthong, SW Cui, S Ningsanond and HD Goff. Structural characterization, degree of esterification and some gelling properties of Krueo Ma Noy (Crissampelos pareira) pectin. Carbohyd. Polym. 2004; $58,391-400$.

19. Kratchanova M.et al. Isolation, characterization, and modification of citrus pectins. J. BioSci. Biotech. 2012, 1(3): 223-233.

20. Ermias Girma and Mr.Teshome Worku. Extraction and Characterization of Pectin From Selected Fruit Peel Waste; IJSRP. 2016 Edition, Volume 6, Issue 2, February

21. Ranganna S. Handbook of analysis and quality control for fruits and vegetable products (2nd Ed.). New Delhi: McGraw Hill publishing Co. Ltd.(1995); 33-43.

22. Maazullah Khan et al. Optimization of Process Conditions for Pectin Extraction from Citrus Peel. Science, Technology and Development; (2015); 34 (1): 9-15

23. Ania A.O., Mustapha M., Barau O.A., Mamman, Amina Z., Hauwa H., Hauwa M.S.U and Yagana B.A. Extraction and characterization of pectin from peels of lemon (citrus limon), grapefruit (citrus paradise) and sweet orange (Citrus sinensis). British Journal of Pharmacology and Toxicology, (2012); 3(6) 259262

24. Canteri-Schemin M.H., Ramos Fertonani H.C., Waszczynskyj N., Wosiacki G. Extraction of pectin from apple pomace, Brazilian Archives of Biology and Technology, (2005); 48 (2), 259-266.

25. Xue Z.H., Zhang X., Zhang Z.J., Liu J.H., Wang Y.F., Chen D.X., Long L.S. Optimization of Pectin Extraction from Citrus Peel by Response Surface Methodology, Food Science, (2011); 32 (18), 128-132.

26. Renard C.M.G.C., Crepeau M.J., Thibault J.F. Structure of repeating units in the rhamnogalacturonic backbone of apple, beet and citrus pectins, Carbohydrate Research, (1995); 275, 155-165.

27. Masmoudi M., Besbes S., Chaabouni M., Robert C., Paquot M., Blecker C., Attia H. Optimization of pectin extraction from lemon byproduct with acidified date juice using response surface methodology, Carbohydrate Polymers, (2008); 74, 185-192.

28. W. Elizabeth Devi, 2014, Extraction of Pectin from Citrus Fruit Peel and Its Utilization in Preparation of Jelly, International Journal of Engineering Research \& Technology, (2014); 3- 1930. 